\title{
Outcome of prenatally diagnosed anterior abdominal wall defects
}

\author{
P A Boyd, A Bhattacharjee, S Gould, N Manning, P Chamberlain
}

\begin{abstract}
One hundred consecutive cases of confirmed anterior abdominal wall defect, identified prenatally in the Oxford Prenatal Diagnosis Unit over 11 years, were studied. Fifty nine per cent of cases were suspected omphaloceles and $41 \%$ suspected gastroschisis. Fifty four per cent of omphaloceles were accompanied by other defects compared with $5 \%$ of those with gastroschisis. Overall, $29 \%$ of fetuses with omphalocele had an abnormal karyotype, and of those with another abnormality identified on scan (excluding four cases with no karyotype performed), $54 \%$ had an abnormal karyotype. Of the 27 cases with suspected isolated omphalocele, 14 were live born, all of whom have survived. If the 11 whose parents opted for termination of pregnancy are excluded, survival to birth was $88 \%$. Six of the suspected isolated omphaloceles have Beckwith Wiedemann syndrome (BWS). Eight $(57 \%)$ of the live born babies with omphaloceles had major problems up to the age of 2 , but only one (7\%) has long term major problems. This child has BWS and is deaf.

Of the 39 cases of suspected isolated gastroschisis, $33(85 \%)$ pregnancies resulted in live birth and one in neonatal death after surgery. Survival rate (excluding terminated pregnancies) was $97 \%$. Gastroschisis was associated with a younger maternal age than omphalocele $(p<0.001)$ and lower birthweight centile $(\mathbf{p}<0.01)$.
\end{abstract}

Fifteen per cent of the gastroschisis babies had major problems up to the age of 2 years and $12 \%$ long term developmental problems. Ninety three per cent of the omphalocele babies and $88 \%$ of those who had gastroschisis have no long term problems. Over the study period there have been major changes in scanning equipment and expertise. Since 1991 no woman with a suspected isolated lesion has opted for termination of pregnancy.

(Arch Dis Child Fetal Neonatal Ed 1998;78:F209-F213)

Unit, The Wiagnosis Centre, Oxford

Radcliffe Hospital, Oxford OX3 9DU

P A Boyd

A Bhattacharjee

N Manning

P Chamberlain

Department of Paediatric Pathology S Gould

Correspondence to: Dr Patricia Boyd.

Accepted 28 October 1997

Keywords: omphaloceles; gastroschisis; BeckwithWiedemann syndrome; deafness

Anterior abdominal wall defects (omphalocele and gastroschisis) are now frequently diagnosed prenatally using real-time ultrasound scanning. ${ }^{2}$ Prenatal diagnosis allows for delivery in a centre with appropriate neonatal surgical facilities; it also allows parents time to come to terms with the fact that their baby has a malformation and to be prepared for the most likely clinical course following delivery. Accurate prenatal assessment may also indicate the presence of other structural anomalies or a chromosomal abnormality. Some parents may opt for termination of pregnancy, particularly when multiple abnormalities are present.

There have been many reports on antenatal detection of anterior abdominal wall defects and their association with other defects, ${ }^{1-5}$ but information on survivors from prenatally diagnosed defects beyond the initial surgery is sparse. The purpose of this study was to assess the accuracy of the prenatal sonographic diagnosis of anterior abdominal wall defects and the likely pregnancy outcome, with particular emphasis on complications occurring in early childhood. This information should allow for more up to date and effective counselling for the parents of a fetus identified before birth as having such a defect.

\section{Methods}

A retrospective study of all prenatally suspected and postnatally confirmed anterior abdominal wall defects seen and delivered between January 1985 and December 1995 in the prenatal diagnosis unit at the Oxford Radcliffe Women's Centre were identified from ultrasound records and the local Register of Congenital Malformations. These included cases booked for delivery in Oxford and also those referred for a second opinion from elsewhere in the Oxford Region. Cases were divided into four groups: suspected isolated omphalocele; suspected omphalocele plus other abnormality; suspected isolated gastroschisis; and suspected gastroschisis plus other abnormality.

Post mortem examination reports were obtained from those cases resulting in termination of pregnancy, intrauterine or neonatal death. For those pregnancies that continued and resulted in a live born child, information was obtained from the paediatric records, GP, and from a questionnaire on long term morbidity sent to parents.

Continuous variables were compared using 
Table 1 Outcome of pregnancy in 100 cases of prenatally diagnosed anterior abdominal wall defect

\begin{tabular}{lrllll}
\hline Initial scan diagnosis & $n=$ & $\begin{array}{l}\text { Suspected } \\
\text { isolated } \\
\text { omphalocele }\end{array}$ & $\begin{array}{l}\text { Suspected omphalocele } \\
+ \text { other abnormality }\end{array}$ & $\begin{array}{l}\text { Suspected isolated } \\
\text { gastroschisis }\end{array}$ & $\begin{array}{l}\text { Suspected } \\
\text { gastroschisis }+ \text { other } \\
\text { abnormality }\end{array}$ \\
\hline $\mathrm{n}=$ & 100 & 27 & 32 & 39 & 2 \\
Number opting for TOP & 45 & 11 & 27 & 5 & 2 \\
Number resulting in IUD or SB & 3 & 2 & 1 & 0 & 0 \\
LB & 52 & 14 & 4 (including 1NND) & 34 (including 1NND) & 0 \\
\hline
\end{tabular}

$\mathrm{TOP}=$ Termination of pregnancy; IUD=Intrauterine Death; NND=Neonatal Death; SB =Stillbirth; LB=Livebirth

Among these was one false positive diagnosis of a suspected gastroschisis in one fetus of a twin pregnancy that was scanned initially at 13 weeks of gestation. Discordant growth was also present. Amniocentesis was performed at 15 weeks of gestation because of the mother's age (39 years). Intrauterine death of the smaller twin occurred at 17 weeks and spontaneous miscarriage of both fetuses at 20 weeks of gestation. Post mortem examination confirmed significant growth discordance and normal fetal anatomy in both twins.

In the remaining 100 cases the antenatally suspected anterior abdominal wall defects were confirmed after delivery. Among the 100 cases forming the study population for this report, 59 were suspected omphaloceles and 41 suspected gastroschises.

ANTENATALLY SUSPECTED OMPHALOCELES Of the 59 omphaloceles, $27(46 \%)$ were considered to be isolated lesions and $32(54 \%)$ to have additional anomalies. The outcome of these pregnancies is shown in table 1 .

Of the 59 antenatally suspected omphaloceles, 18 were live births. Of these, 14 were in fetuses with a suspected isolated lesion and four in fetuses with suspected omphalocele plus additional anomalies.

SUSPECTED ISOLATED AMPHOLOCELE

There were 27 antenatally suspected isolated omphaloceles. Examination following delivery confirmed an isolated omphalocele in 26 ; in the remaining case a gastroschisis was identified after termination of the pregnancy. Eleven cases resulted in termination of pregnancy, two intrauterine deaths, and 14 live births. Of the 11 terminated pregnancies, two had karyotypic abnormalities (one trisomy 13 scanned at 11 weeks before chorionic villus sampling; one trisomy 18 mosaic diagnosed at 20 weeks after amniocentesis performed because of a small, apparently isolated omphalocele. Post mortem examination confirmed the omphalocele and also identified bilateral talipes and overlapping fingers.) The two intrauterine deaths occurred at between 22 and 24 weeks of gestation; amniocentesis had been performed in both pregnancies.

Details of gestational age at delivery, mode of delivery, birthweight centile and length of hospital stay in this group are shown in table 2 . Among the 14 live births in this group, seven had additional abnormalities identified postnatally. One of the seven with additional anomalies identified postnatally had a $4 \times 3 \mathrm{~cm}$ anterior diaphragmatic hernia identified at 13 months of age when the child underwent surgery for revision of the abdominal wall scar. Six children in this group had BWS diagnosed because of omphalocele occurring with macrosomia (five of them had a birthweight greater than the $90^{\text {th }}$ centile); macroglossia ( all six, with one requiring surgical reduction in the first year); hypoglycaemia (3); naevus flammus (4); ear crease (3).

Primary closure of the abdominal wall defect was performed in eight of the 14 cases. In a further five a two stage repair using a silactic silo before final closure was used. In the remaining case the abdominal defect was manually reduced.

Four of the 14 children have had no problems after their initial surgery. Two had inguinal herniae repaired and eight had major problems during the first two years; four related to BWS; one had a diaphragmatic hernia diagnosed (see above) repaired at 13 months; one had a hiatus hernia and major feeding problems requiring a gastrotomy up to age 12 months; two had major feeding problems and multiple operations, one requiring 12 operations and 22 weeks in hospital.

Table 2 Details of birth and initial hospital stay

\begin{tabular}{llll}
\hline Initial scan diagnosis & $\begin{array}{l}\text { Suspected isolated } \\
\text { omphalocele } n=14\end{array}$ & $\begin{array}{l}\text { Suspected omphalocele }+ \text { other } \\
\text { abnormality } n=4\end{array}$ & $\begin{array}{l}\text { Suspected isolated } \\
\text { gastroschisis } n=34\end{array}$ \\
\hline $\begin{array}{l}\text { Median weeks' gestation at delivery } \\
\text { Vaginal delivery }\end{array}$ & 38 & 36 & 37 \\
Caesarean section & 8 & 3 & 16 \\
$\begin{array}{l}\text { Birthweight centile } \\
<10\end{array}$ & 6 & 1 & 18 \\
$10-<50$ & 2 & 2 & 16 \\
$50-90$ & 4 & 1 & 14 \\
$>90$ & 3 & 1 & 4 \\
Length of initial hospital stay & 5 & 0 & 0 \\
$<28$ days & 8 & 1 (NND) & 17 (1NND) \\
$>1-4$ months & 5 & 3 & 2 \\
$\quad>6$ months & 1 & 0 & 2 \\
Additional congenital anomalies & 7 & 4 & $(1$ Congenital heart disease- \\
noted after birth & $(6$ BWS; 1 diaphragmatic & $(1$ cloacal extrophy; 3 features & NND after surgery; 1 VSD \\
& hernia, pentalogy of & of pentalogy of Cantrell) & closed spontaneously) \\
\hline
\end{tabular}


Table 3 Clinical details of those cases resulting in live birth

\begin{tabular}{llll}
\hline Initial scan diagnosis & $\begin{array}{l}\text { Suspected isolated } \\
\text { omphalocele }\end{array}$ & $\begin{array}{l}\text { Suspected } \\
\text { omphalocele }+ \\
\text { other abnormality }\end{array}$ & $\begin{array}{l}\text { Suspected isolated } \\
\text { gastroschisis }\end{array}$ \\
\hline Total No of cases & 14 & 4 & 34 \\
Median age of mother in years & 31 & 27 & 21 \\
$\quad$ Range & $21-39$ & $19-30$ & $17-39$ \\
Median weeks' gestation at diagnosis & 19 & 19 & 18 \\
$\quad$ Range & $13-36$ & $14-19$ & $14-37$ \\
\hline
\end{tabular}

Now aged 7, her mother describes her as a normal healthy child.

Longer term follow up of these children aged from 2 to 11 years (mean 6 years) shows that they are developing normally according to their parents and general practitioner and hospital records. All but one of those who have reached school age attend main stream schools. One child who has BWS attends a special school because of his deafness.

\section{SUSPECTED OMPHALOCELE PLUS OTHER} ABNORMALITY

Thirty two antenatally suspected omphaloceles were also thought to have additional anomalies. Examination after delivery confirmed an omphalocele in all cases. Fifteen of the 32 cases had associated karyotypic abnormalities and the remaining 17 cases had various associated structural abnormalities. Karyotypic abnormalities included trisomy 18 (10); trisomy 13 (3), and triploidy (2). Associated structural anomalies in the other 17 cases (13 of which

101 antenatally suspected cases AAWD

1 gastroschisis not confirmed postnatally

100 postnatally confirmed AAWDs

59 suspected omphalocel

41 suspected gastroschisis
32 omphalocele + other structural abnormality

\begin{tabular}{l}
\hline 39 confirmed \\
isolated \\
gastroschisis
\end{tabular}

2 gastroschisis + other structura abnormality

\begin{tabular}{|l|l|}
\hline $\begin{array}{l}1 \text { isolated } \\
\text { gastroschisis } \\
\text { diagnosed at PM }\end{array}$ & $\begin{array}{l}26 \text { confirmed } \\
\text { isolated } \\
\text { omphalocele }\end{array}$ \\
\hline
\end{tabular}
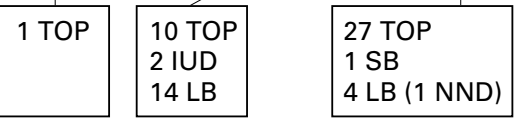

5 TOP

34 LB (1 NND)
2 TOP

had normal karyotype and four in which karyotyping was either not done or failed) included neural tube defects (6); amnion rupture (2); features of pentalogy of Cantrell (5); short cord and kyphoscoliosis (2); and bladder exstrophy (2). Twenty seven pregnancies in this group resulted in a termination and one in a stillbirth.

Four live births occurred. The gestational age at delivery, mode of delivery, birthweight centile and length of hospital stay are shown in table 2. Associated anomalies, suspected prenatally and confirmed postnatally, included cloacal exstrophy in one case and diaphragmatic hernia plus congenital heart disease in three cases. The child with cloacal exstrophy, now aged 10 years, had an ileostomy and cystotomy performed at birth. She is developmentally normal but has continual orthopaedic problems with abnormal gait and repeated urinary infections.

The remaining three cases in this group all have features of pentalogy of Cantrell. This brings to six (two of which resulted in termination of pregnancy) the total number of cases with features of this syndrome in this series. Three of them have been reported before. ${ }^{6}$ In the remaining three cases in this group neonatal death occurred from bronchopulmonary dysplasia-before surgery in one-the two surviving children with features of pentalogy of Cantrell have had multiple hospital admissions and repeated surgical procedures. One of them, a boy, was tube fed until the age of 2 years. Now aged 4 , he has a gastrotomy and recently had a renal stone removed. In spite of the major feeding problems and surgery to abdominal wall and heart, his mother describes him as a cheerful and normal child who will soon start at a mainstream primary school.

ANTENATALLY SUSPECTED GASTROSCHISIS

Of the 41 antenatally suspected cases of gastroschisis, 39 were thought to be isolated lesions and two to be associated with other anomalies. The outcome of these pregnancies is shown in table 1 .

There were 34 live births. All the live births were in babies with an isolated lesion suspected prenatally. Details of gestational age, mode of delivery, birthweight centile and length of hospital stay are shown in table 3. Mothers of babies with gastroschisis were significantly younger than mothers of babies with omphalocele $(\mathrm{p}<0.001)$ (table 3$)$. There were no significant differences in the gestational ages at diagnosis or delivery between the groups, although the birthweight in babies with gastroschisis was significantly lower than in babies with omphalocele $(\mathrm{p}<0.01)$.

SUSPECTED ISOLATED GASTROSCHISIS

The antenatal diagnosis was confirmed in all 39 cases. Five pregnancies were terminated. One baby died in the neonatal period (table 1). In one case death occurred after surgical repair. A congenital heart abnormality was suspected but not confirmed, as permission for a post mortem examination was refused.

Abbreviations TOP $=$ termination of pregnancy; $\mathrm{SB}=$ Still birth; IUD = intrauterine death; NND = Neonatal death; LB = Live birth; AAWD = Anterior abdominal wall defect

Figure 1 Outcome of prenatally diagnosed anterior abdominal wall defects. 
Of the 33 survivors, 26 are now aged over 2 years. Twelve of the $26(46 \%)$ have had no problems following surgical repair of the gastroschisis. Ten had minor problems up to the age of 2 relating to failure to thrive (3), ventral herniae (2), undescended testes (2), constipation (1) and respiratory illness (2). Four had more serious problems up to the age of 2 years; one developed hydrocephalus of postnatal origin; one had an ileostomy performed for ileal atresia; and two had surgery for hiatus herniae. Three of the 26 children $(12 \%)$ have long term problems; hydrocephalus of postnatal origin with slow development; double incontinence and slow development; an undiagnosed syndrome with dysmorphism and slow development.

\section{SUSPECTED GASTROSCHISIS PLUS OTHER}

ABNORMALITY

Associated anomalies were suspected antenatally and confirmed postnatally in two cases. One fetus had cloacal exstrophy with gastroschisis confirmed on external examination, permission for post mortem examination having been declined; the other had severe kyphoscoliosis plus a missing arm (limb body wall complex). The pregnancy was terminated in both cases.

\section{Discussion}

Omphalocele and gastroschisis are usually considered to be distinct abnormalities. The aetiology of each is unclear and there is some controversy concerning pathogenesis. ${ }^{7} \mathrm{Om}$ phalocele is a midline anterior abdominal wall defect with herniation of the abdominal contents into the base of the umbilical cord. It is commonly associated with other abnormalities, particularly cardiac defects and aneuploidy. It may result from failure of migration of lateral and cephalic or caudal folds during the fourth to sixth week after fertilisation. ${ }^{5}$ Gastroschisis is a (usually right sided) paraumbilical defect with evisceration of abdominal contents directly into the amniotic cavity. It may have a vascular cause. ${ }^{8}$ The incidence of omphalocele of 2.5 per 10000 live births ${ }^{4}{ }^{10}$ has probably remained static, although recently Tan et $a l^{1}$ reported regional differences in England and Wales, with more occurring in the North. Chitty and Iskaros ${ }^{11}$ have commented on the difficulties surrounding data collection, particularly for pregnancies that were terminated and for those associated with other malformations. In this study useful data on incidence can only be applied to the few local cases because those referred from other centres do not provide a defined population. For confirmed isolated omphalocele (including five terminated fetuses but excluding intrauterine deaths), there were seven local cases in a period when 71500 deliveries were carried out, giving an incidence of 0.99/10 000. A similar calculation for gastroschisis gives an incidence of $1.3 / 10000$ in this population. If all local cases are included (including those with additional anomalies) the incidence for omphalocele is $3.2 / 10000$ and $1.4 / 10000$ for gastroschisis.
Like others we have seen an increase in the incidence of gastroschisis cases in recent years. ${ }^{1311}$

In this study there were 59 omphaloceles suspected antenatally, $54 \%$ of which had other malformations. Overall, 29\% had confirmed abnormal karyotype with $11(19 \%)$ due to trisomy 18 . Ten of these resulted in termination of pregnancy and one in stillbirth, the mother having opted to continue her pregnancy after trisomy 18 was diagnosed at 17 weeks of gestation. A recent report from the Northern Region $^{13}$ showed similar experience, with $40 \%$ of omphaloceles being associated with other anomalies and $28 \%$ with abnormal karyotype. In our study, of those cases thought to be isolated lesions, one, scanned at 12 weeks of gestation had trisomy 13, and one with trisomy 18 mosaicism, scanned at 20 weeks in 1989 , had talipes recorded at post mortem examination after the pregnancy had been terminated. Thus in cases thought to be isolated and scanned after the first trimester, the risk for trisomy 18 is low and, with improvements in scanning, may now be lower. In this tertiary referral centre accuracy of diagnosis was good; one case (scanned in 1987) thought to be an omphalocele, had a gastroschisis at post mortem examination following termination of pregnancy, and one case of suspected gastroschisis in a growth retarded twin who sustained intrauterine death was not confirmed. Although this study addresses cases identified prenatally, there has been only one unidentified case (an isolated omphalocele) born to a local mother who was scanned at the appropriate time.

Of those with suspected isolated omphalocele, 11 opted for termination of pregnancy, two resulted in intrauterine death, and 14 in live births. If the 11 terminated pregnancies are excluded the survival rate to birth was $88 \%$. Six of the children with isolated omphalocele suspected prenatally were diagnosed postnatally as having BWS, ${ }^{13}$ a very much higher percentage (33\% of all live born omphaloceles) than that reported before..$^{1311}$

Gastroschisis is usually an isolated lesion and not associated with karyotypic abnormality. The findings of young maternal age and low birthweight are consistent with previous studies. $^{1510}$ In this study two out of $41(5 \%)$ cases of gastroschisis were associated with other major malformations; five pregnancies with isolated gastroschisis were terminatedall before 1988. One suspected case of isolated gastroschisis died in the neonatal period after surgery. A congenital heart defect was suspected, but permission for post mortem examination was refused. Overall survival rate for gastroschisis was $97 \%$.

Clausner et $a l^{14}$ recently carried out a 25 year review of 132 patients with anterior abdominal wall defects. They comment on improved results of surgery following the advent of prenatal diagnosis, partly because of selective abortion of the more severe cases with multiple abnormalities. They conclude that development and quality of life are not significantly reduced after survival of an isolated defect. 
During the 11 years when these cases were seen, there have been major changes in scanning equipment and expertise as well as in obstetric and paediatric management of women known to be carrying a baby with such a defect. For example, all the cases resulting in termination of pregnancy for suspected isolated lesions occurred before 1991. Changes in obstetric practice are seen in the number of caesarean sections performed in different years. Before 1990, 13 of 15 (87\%) suspected isolated gastroschisis babies were delivered by caesarean section compared with five of 19 cases $(26 \%)$ after 1990 . In the suspected isolated omphalocele group four out of six $(67 \%)$ babies delivered before 1990 were by caesarean section compared with two out of eight $(25 \%)$ after 1990.

This study has shown that accuracy of antenatal diagnosis in a tertiary referral centre is good and, despite the fact that many babies have major clinical problems during the first two years of life, $93 \%$ of the babies born with an omphalocele and $88 \%$ of those with gastroschisis have no long term problems. Although the aetiology of both disorders remains debatable, the extraordinarily high incidence in the omphalocele group of BWS forcibly suggests that overgrowth of viscera is one predisposing mechanism. This is in keeping with the known incidence $(77 \%)$ of omphalocele in babies with BWS. ${ }^{13}$
We thank Sisters Annona Galliard and Nora Jones for help in tracing cases and pregnancy outcomes.

1 Tan KH, Kilby MD, Whittle MJ, Beattie BR, Booth IW, Botting BJ. Congenital anterior abdominal wall defects in
England and Wales between 1987-93. BMF 1996;313:9036 .

2 M.

orrow RJ, Whittle MJ, McNay MB, Raine PAM, Gibson AAM, Crossland J. Prenatal diagnosis and management of anterior abdominal wall defects in the West of Scotland. Prenatal Diagnosis 1993;13:111-15.

3 Torfs C, Curry C, Roeper P. Gastroschisis. Paediatrics 1990;116:1-6.

4 Calzolari E,Bianchi F, Dolk $H$, Milan $M$, and the EUROCAT Working Group. Omphalocele and gastroschisis in Europe: a survey of 3 Million Births 1980-1990. Am F Med Genet 1995; 58:187-94.

5 Curry CJR, Honore L, Boyd E. The ventral wall of the trunk. In: Stevenson RE, Hall JG, Goodman RM, eds. Human malformations and related anomalies. Vol 11. Oxford: OUP, 1993:869-91.

6 Siles C, Boyd PA, Manning N, Chamberlain P. Omphalocele and Pericardial Effusion: Possible sonographic markers for the pentalogy of Cantrell or its variants. Obstet markers for the pentalogy

7 Kluth D, Lambrecht W. The pathogenesis of omphalocele and gastroschisis. An unsolved problem. Pediatr Surg Int 1996;11:62-6.

8 Hoyme HE, Higginbottom MC, Jones KL. The vascular pathogenesis of gastroschisis: Intrauterine interruption of the omphalomesenteric artery. F Paediatr 181;98:228-31.

9 Yudkin PL, Aboualfa M, Eyre JA, Redman CWG, Wilkinson A. Early Hum Dev 1987;15; 45-52.

10 Baird PA, MacDonald EC. An epidemiologic study of congenital malformations of the anterior abdominal wall in more than half a million consecutive live births. Am $\mathcal{F}$ Hum Genet 1981;33:470-8.

11 Chitty L, Iskaros J. Congenital anterior abdominal wall defects. BMF 1996;313:891-2.

12 Dillon E, Renwick M. The antenatal diagnosis and management of abdominal wall defects: the northern region experience. Clin Radiol 1995;50:855-8.

13 Elliott M, Maher ER. Beckwith-Wiedemann syndrome. 7 Med Genet 1994;31:560-4.

14 Clausner A, Lukowitz A, Rump K, Berger S, Wurfel A. Treatment of congenital abdominal wall defects - a 25 year review of 132 patients. Pediatr Surg Int 1996;11:76-81. 